\title{
Valuation of Inter-firm Relationships in the Telecommunications Industry: Typology and Market Responses
}

\author{
Noriaki Shiraishi \\ Tokyo Institute of Technology \\ E-Mail: shiraishi-n@pro.odn.ne.jp \\ Junichi Iijima \\ Tokyo Institute of Technology \\ E-Mail: iijima.j.aa@m.titech.ac.jp
}

\begin{abstract}
This paper discusses a typology and evaluations of inter-firm relationships in the telecommunications industry. The authors define inter-firm relationships as a broad range of relationships including strategic alliances, joint ventures, and mergers and acquisitions (M\&A) or other equity-based relationships. Forming relationships and selecting partners are the two most important issues for managers when arranging inter-firm relationships and these are also important subjects for research in this area. The authors empirically analyzed inter-firm relationships by evaluating short-term stock-market responses to announcements about the formation of such relationships. These evaluations follow typologies previously proposed by the authors, which are explained in this paper. Three hypotheses are proposed and examined regarding general market responses and the difference in responses between each defined type of relationship and market.

The results from evaluations revealed that market responses were generally not favorable in the short term in contrast to general understanding of market responses. However, the authors found significant differences in responses between the relationship categories of the framework. Practical implementations were obtained where managers in the industry had to take into account how the stock market responded to the formation of inter-firm relationships when they developed their corporate strategies. The results also demonstrated the validity of the proposed framework and suggested it should be useful to enable further analysis of this industry.
\end{abstract}

Keywords: Telecommunications, Alliances, M\&A, Typology, Evaluation 


\section{INTRODUCTION}

Telecommunications firms, often called telecommunications carriers, have actively engaged in strategic alliances, equity arrangements, joint ventures, and mergers and acquisitions (M\&A). In this paper, the authors have called these arrangements inter-firm relationships, based on the definition by Yoshino and Rangan (1995). Inter-firm relationships in the industry had become common by the mid-1980s in the United States and other industrialized countries soon joined this trend as deregulation advanced in the 1990s (Joshi et al., 1998, Trillas, 2002). Managers in the telecommunications industry should therefore consider the development of inter-firm relationships as their most important strategic activities, and a present matter of importance to them is evaluating inter-firm relationships. Managers engaged in developing inter-firm relationship strategies must decide whether to form inter-firm relationships, and which firms to target as potential partners. Such decisions must offer them the opportunity of improving the firm's competitive scope, increasing profitability, or gaining positive acceptance by stakeholders. Therefore, effective ways of evaluating inter-firm relationships are key tools for such managers and such tools would also be valuable to enable academic studies of these relationships.

Although research has been conducted on inter-firm relationships in the telecommunications industry (e.g. Graack, 1996, Oh, 1996, Baroncelli, 1998, ChanOlmsted and Jamison, 2001, Curwen, 2001, Faulhaber, 2002, Jamison and ChanOlmsted, 2002), this has mainly focused on explaining specific relationships and discussion has mostly focused on rather qualitative standpoints. In this research, the authors have attempted to conduct quantitative evaluations of inter-firm relationships in the telecommunications industry and to find critical factors that should be considered by managers when developing strategies or by researchers who are analyzing the industry.

The authors previously showed that major telecommunications carriers tend to select M\&A or equity-based relationships as strategic activities rather than entering into strategic alliances to improve their competitive positions. They also proposed a typology (geographical expansion, segment expansion, and business diversification) as an analytical framework for understanding inter-firm relationships within the industry and demonstrated that this typology would help managers and researchers recognize appropriate strategic directions for firms based on our findings regarding the characteristics of the telecommunications industry (Shiraishi and Iijima, 2008a).

This paper discusses the characteristics of the industry and evaluations of interfirm relationships within it. It also attempts to derive a useful implementation for 
managers to develop strategies on inter-firm relationships in the industry. It also focuses on stock-market responses to enable inter-firm relationships to be evaluated and adopts an event-study methodology—understood as a standard methodology both for practical and research analyses.

The next section reviews the characteristics of the telecommunications industry and presents a typology for inter-firm relationships in the industry proposed by the authors. The third section discusses methodologies for evaluating inter-firm relationships in the industry and states our hypotheses. The fourth section explains the data and calculations the authors used. The results are discussed in the fifth section. The last section presents our conclusions and issues that remain for further research.

\section{CHARACTERISTICS OF THE TELECOMMUNICATIONS INDUSTRY AND TYPOLOGY OF INTER-FIRM RELATIONSHIPS}

\section{Characteristics of the telecommunications industry}

The industry's characteristics have been analyzed and discussed mainly from economic- and regulatory-environment standpoints (Brock, 1998, Kahn, 1997, Laffont and Tirole, 2001, Vogelsang and Mitchell, 1997). These researchers pointed out that the industry has distinctive features—scale and scope, network externality, and bottleneck monopolies — and regulatory systems in the industry are correlated to these features. Of these features, Shiraishi and Iijima identified two industry characteristics that seem to intensely affect a firm's strategic behavior and choice of inter-firm relationships through reviewing discussions and observations (2008a). The first is that firms tend to pursue expansion of their networks and services. This is due to the nature of telecommunications services, much like other public utility businesses, where economies of scale and scope in providing services cause the telecommunications market to behave much like a natural monopoly. The second characteristic of the industry is regulatory systems, which had been developed because of the first characteristic, and these affect a firm's strategic behavior and choices of inter-firm relationships.

In addition to the characteristics of regulatory systems, another characteristic of the industry can be identified, which is different to that of other public-utility businesses. The telecommunications market has historically been defined as a combined market-local, long distance (including or excluding international connectivity), and mobile services-and strict barriers have been raised between individual markets, where firms have been legally restricted to one or limited types of 
services. These regulatory systems have also created barriers preventing new firms from entering markets and restricting foreign investors. Still, it is important to take into account deregulation initiatives such as the Telecommunications Act of 1996 in the United States and further deregulation efforts in the EU, Japan, and other countries.

The next subsection explains the typology and framework for evaluating interfirm relationships in the telecommunications industry based on the previously mentioned characteristics.

\section{Typology for inter-firm relationships}

As Barney (2002) pointed out, strategic alliances, joint ventures, and M\&A are important alternatives in firms' strategic activities. However, strategic alliances and other inter-firm relationships, such as those through M\&A or equity-based relationships, have usually been generally discussed independently of one another (Yoshino and Rangan, 1995). The telecommunications industry, in contrast, is shaped by the two characteristics mentioned in the previous subsection, and telecommunications firms are usually motivated to expand their networks. This leads firms to engage in strategic activities aimed at expanding the scale of their businesses. This observation is supported by actual data on the inter-firm relationships telecommunications carriers have developed (Shiraishi and Iijima, 2008a).

Based on these findings, the authors discovered that a different perspective on this categorization would be appropriate and here they propose a typology for interfirm relationships in the industry that differs from typical typologies such as that by Yoshino and Rangan (1995) or that by the U.S. Federal Trade Commission (Barney, 2002). The proposed typology is correlated to the industry-market structure discussed by Kahn (1997) and Vogelsang and Mitchell (1997)—local, long distance, international, and mobile services-and is also consistent with existing theory regarding corporate strategy or inter-firm relationships such as that by Porter (1985) and Barney (2002). Consequently, three dimensions and directions for strategic relationships were defined: geographical expansion, segment expansion, and business diversification (Figure 1). The authors demonstrated the validity of the typology for inter-firm relationships between telecommunications carriers and discussed that the typology provides an analytical framework for firms to evaluate the practicality of forming future inter-firm relationships (Shiraishi and Iijima, 2008a). 


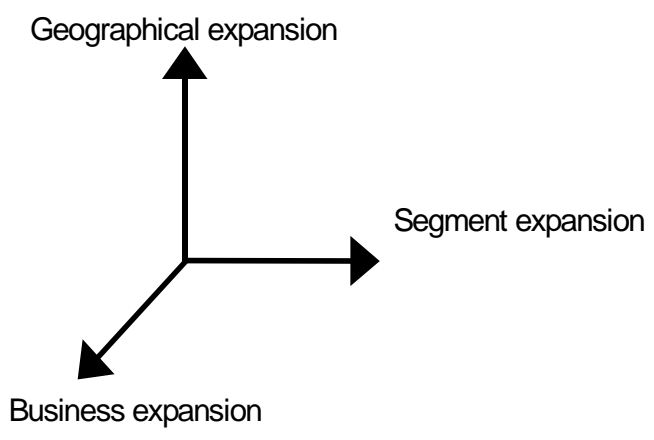

Figure 1 Three-dimensional typology of inter-firm relationships

\section{EVALUATION OF INTER-FIRM RELATIONSHIPS AND HYPOTHESES}

\section{Focused on inter-firm relationships and methodology}

This section describes target relationships and the methodology for analyzing inter-firm relationships and its application. First, this research focused on inter-firm relationships conducted by mega-carriers with annual revenues exceeding one billion U.S. dollars, or those with businesses of equivalent size. This focus was based on access to information by businesses in inter-firm relationships and the international comparability of cases.

Various methodologies may be proposed for the purposes of evaluating relationships. However, managers in this field expect such methodologies to provide objective facts and information based on disclosed or verifiable data as they are accountable to shareholders. For this reason, the authors developed a methodology of valuation based on financial information. Such information can include sales/revenue variations, profitability, asset-utilization efficiency, variations in market valuations, or other related information, but the stock-market response is the most frequently discussed and applied measure for evaluating inter-firm relationships; the studies by Ely and Song (2000) and Hart and Apilado (2002) are typical examples.

This research therefore evaluated inter-firm relationships by observing stockmarket responses. Inter-firm relationships were evaluated based on methodology involving study of events - whether the share prices of the concerned firms rose or fell after the relationship was announced compared to prices over particular preceding terms of time. The reason an event-driven study was applied was that the methodology is well developed and one of the most widely applied to assess the corporate value of inter-firm relationships in other industries (Kale et al. 2002). 
In addition to the typology, the authors focused on countries where individual firms had their headquarters. This was justified by the fact that two-thirds of the carriers involved in the selected cases were headquartered in the USA or Canada, with most of the remainder headquartered in EU countries. The authors therefore recognized the need to evaluate whether there were differences in the market responses of US/Canada-based carriers and the responses of EU-based firms; such differences could reveal differences in the conditions or structures of these two large telecommunications markets.

\section{Hypotheses}

The authors established three hypotheses to evaluate inter-firm relationships.

The first was correlated to general responses to inter-firm relationships not limited to the telecommunications industry. Research in other industries, such as financial and pharmaceutical industries have shown that alliances and M\&A activities create value. In other words, market responses to public announcements of alliances or M\&A are generally positive and the market value has increased (Hill, 1997, Kelm et al., 1995, Mitchell et al., 1996). Inter-firm relationships are generally aimed at strengthening firms' competitiveness and business performance, and consequently increasing returns to shareholders. Within this context, the first hypothesis can be established where the market response to announcements of inter-firm relationships in the telecommunications industry will usually be positive as well as in other industries.

Hypothesis H-1: Inter-firm relationships are positively valued by the stock market - stock prices will rise after the announcement of such relationships.

The second hypothesis that was established was correlated to the typology of inter-firm relationships in the industry. As discussed in the preceding section, the authors introduced a three-dimensional model of expansion and defined the directions of expansion based on the geography, segment of the industry, and business. This model demonstrates that managers choose to form inter-firm relationships within the category of the proposed typology when establishing strategies for them. It is therefore important to evaluate whether there are any differences in the stock market responses in any of the directions in the proposed typology.

The telecommunications industry is generally considered a natural monopoly, and regulatory systems governing it are mainly designed to overcome problems arising from this characteristic (Kahn, 1997, Vogelsang and Mitchell, 1997).

Within the directions of geographical expansion, segment expansion, and business diversification, the characteristics of the first direction mean that 
telecommunications carriers aim at simply enhancing their business scale by entering into new areas in the same businesses. However, segment expansion and business diversification can be likened to entering different businesses. Wilcox et al. (2001) found useful results from telecommunications firms entering different business areas. Although their target of discussion was different, they found that market responses to telecommunications firms entering extremely different businesses were less valued than them entering business categories that were more closely related.

These findings imply that geographical expansion seems the most effective way of enhancing business opportunities by exploiting the nature of the industry. Our second hypothesis therefore was that the market response to announcements of interfirm relationships enabling geographical expansion will be positive.

Hypothesis H-2: Geographical expansion is positively valued by the stock market - the stock price will rise most after an inter-firm relationship is announced enabling geographical expansion.

The third hypothesis that was established was correlated to the additional focus explained in the section above. It is therefore important to find whether stock-market responses in the U.S.A and Canada differ from those in other countries.

Deregulation in the telecommunications industry started in the U.S.A and Canada and then spread to other countries, and many telecommunications firms involved in past inter-firm relationships have been based in the U.S.A or Canada. It is therefore natural to assume that conditions in the telecommunications industries in these countries make it more probable for the firms involved to enter into inter-firm relationships to strengthen their competitiveness and business performance compared to other countries. Although there have been no comparative evaluations in other countries, the authors based their hypothesis on the fact that market responses to announcements of inter-firm relationships by U.S. and Canadian firms are more positively valued than those by firms based elsewhere.

Hypothesis H-3: Inter-firm relationships by US or Canadian firms are more positively valued by the stock market than those by firms in other countries - The stock price of U.S./Canadian firms will rise more than that of other firms after they have announced inter-firm relationships.

The following sections describe the evaluation procedure and explain how the authors tested these hypotheses. 


\section{DATA AND PROCEDURE FOR EVALUATION}

To evaluate inter-firm relationships in the telecommunications industry, the focus was on the inter-firm relationships (equity-based alliances and M\&A combinations) of mega-carriers with annual revenues exceeding one billion U.S. dollars, or those with equivalent-size businesses, from 1985 to 2002. The data were collected from the Financial Times database. Although the selected time frame might not seem very recent, it did cover the periods of deregulation in the targeted countries discussed earlier and in other significant countries as in our previous research. The daily stockprice data for all carriers, combined with data on alliance announcements, were gathered from the stock-market data. Constraints in collecting the data included problems with unlisted companies and inadequate information on price adjustments. In total, data were collected for 40 companies, all of which were listed on the U.S. stock exchange, and the S\&P 500 was selected as the market index to calculate the market model. The authors focused on market reactions as those that were reflected in the stock prices of firms being bid for or being acquired, as they assumed that the market response would be more directly related to the prospects of these firms. Evaluations were done according to where individual firms' headquarters were located, in addition to the proposed typology, taking into consideration the characteristics of the gathered data.

This study used the market model and an event-study methodology with daily stock-price data. The event-study methodology was originally developed for studying financial businesses (MacKinlay, 1997, Campbell et al., 1997), and is often used to evaluate market responses. Rad and Van Beek (1999) and Bessler and Murtagh (2002) are example researchers who applied this methodology. However, very few studies in the telecommunications industry have been done using such quantitative evaluations; the research by Wilcox et al. (2001) being one of the few cases where event-study methodology has been applied to this industry.

Stock-price data as well as the dates all alliance and M\&A events were announced were collected from the Financial Times database for this research. This database was chosen because the authors aimed to focus on evaluating market responses based on firms' announcements disclosed to the public. Also, this data source was both directly connected with such information and is recognized as being one of the most reliable sources on this topic. Other major journals and academic databases could be considered as potential data sources, but the database offered the best single access to financial viewpoints regarding events in which the authors were interested. 
Daily stock-price data were used to calculate daily returns. Price data from periods ranging from 120 to 6 trading days prior to each announcement date were used to estimate the market model representing the average normal return for each stock. All stock-price data were adjusted to reflect dividends and stock splits. Various periods have been used to estimate the market model in previous studies, e.g., Davidson and Worrell (1992) used a period of 9 months, while Koh and Venkataraman (1991) used one of two days. However, most studies have used several months of data (e.g., Kelm et al., 1995; Wilcox et al., 2001), and the authors used a similar term in this research.

The test period for evaluating the market response to each announcement was fixed from -1 to +5 days (a total of 7 days) from the day of announcement, and this period was used to calculate the abnormal return (AR) and the cumulative abnormal return (CAR).

$\mathrm{AR}$ is defined as the difference between the actual return and the estimated normal return calculated with the market model,

$$
A R_{j}=R_{j t}-\left(\alpha_{j}+\beta_{j} R m t\right)
$$

where $R_{j}$ is the return for stock $\mathrm{j}$ on day $\mathrm{t}$, and $R_{m t}$ is the return for the market on day t. $\alpha_{j}$ and $\beta_{j}$ are parameters defined for each stock $\mathrm{j}$ that are calculated from daily stock-price data.

The CAR for each stock is calculated based on daily abnormal returns:

$$
\operatorname{CAR}_{j}\left(t_{1}, t_{2}\right)=\sum_{t=t}^{t} A R j t
$$

The authors used the $t$-statistic to test the significance of results from these two calculations. In this study, the authors mainly examined cross-sectional variations by forming portfolios based on the attributes of individual cases. Aggregate CAR across firms was obtained as

$$
\operatorname{CAR}\left(t_{1}, t_{2}\right)=\frac{1}{n} \sum_{j=1}^{n} \operatorname{CARj}\left(t_{1}, t_{2}\right)
$$

The t-statistic was also used to test the significance of results from the above calculations.

To evaluate market responses, the authors calculated CAR from 0 to +5 days. 


\section{RESULTS AND DISCUSSION}

\section{Results}

The market reaction to firms categorized with our three-dimensional model of expansion is listed in Table 1 and CAR changes within the test period are plotted in Figure 2. Although the CAR values during the test period were slightly positive for the geographical-expansion cases and negative for the segment-expansion cases, these values were not statistically significant. In contrast, the CAR values for business diversification were negative and statistically significant. This indicates a negative response to alliances directed toward business expansion.

Table 2 and Figure 3 compare the CAR values between U.S./Canada-based firms and non-U.S./Canada-based (European) firms. The CAR values for U.S./Canadabased firms were negative and statistically significant at the $1 \%$ level, while the values for non-U.S./Canada-based carriers were not statistically significant.

Table 1 Returns by business expansion/diversification patterns

\begin{tabular}{lcccccc}
\hline & \multicolumn{2}{c}{$\begin{array}{c}\text { Geographical } \\
\text { expansion }\end{array}$} & \multicolumn{2}{c}{ Segment expansion } & \multicolumn{2}{c}{$\begin{array}{c}\text { Business } \\
\text { diversification }\end{array}$} \\
\cline { 2 - 7 } & Return & t-value & Return & t-value & Return & t-value \\
\hline CAR(-5,5) & $0.43 \%$ & 0.21 & $-5.4 \%$ & -0.21 & $-3.27 \%$ & -1.45 \\
\hline CAR(-1,5) & $0.52 \%$ & 0.32 & $-6.10 \%$ & -0.29 & $-1.73 \%$ & $-1.79^{* *}$ \\
\hline CAR(-1,4) & $-0.27 \%$ & -0.18 & $-5.08 \%$ & -0.27 & $-2.56 \%$ & $-2.66^{* * *}$ \\
\hline CAR(-1,3) & $0.52 \%$ & 0.38 & $-4.36 \%$ & -0.25 & $-1.48 \%$ & -1.53 \\
\hline CAR(-1,2) & $0.28 \%$ & 0.23 & $-5.16 \%$ & -0.33 & $-1.59 \%$ & -1.65 \\
\hline CAR(-1,1) & $-0.25 \%$ & -0.24 & $-4.61 \%$ & -0.34 & $-1.83 \%$ & $-1.89^{* *}$ \\
\hline CAR(-1,0) & $0.50 \%$ & 0.58 & $-4.05 \%$ & -0.37 & $-2.12 \%$ & $-2.19^{* * *}$ \\
\hline \#of observation & & 15 & & 11 & & 14 \\
\hline
\end{tabular}

* t-statistics at the 10\% significance level,**5\% level,***1\% level

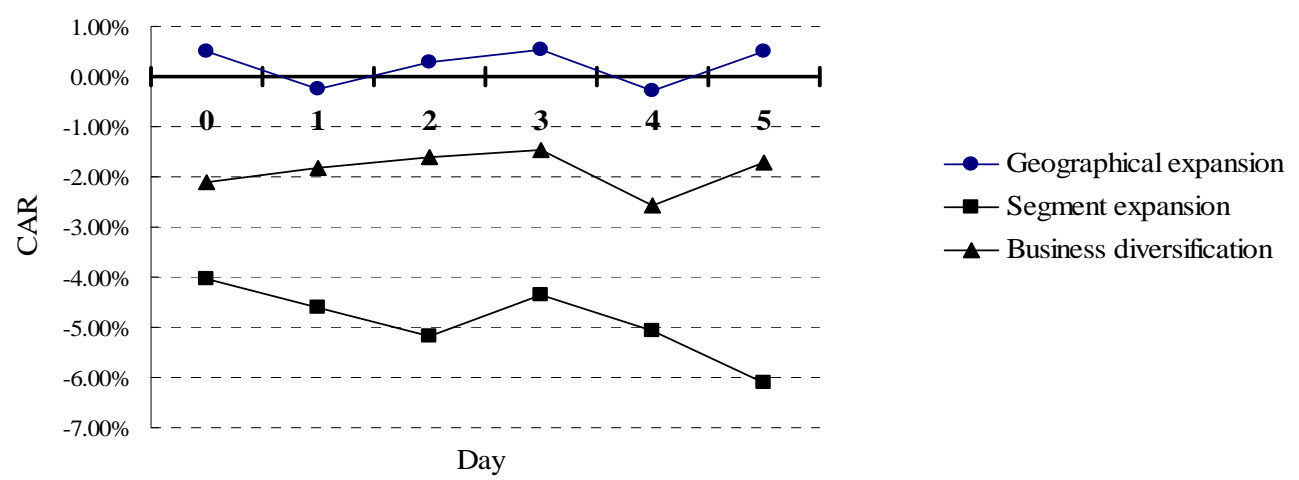

Figure 2 CARs by direction of business expansion 
Table 2 US/Canada vs. Non-US/Canada based carriers

\begin{tabular}{lcccc}
\hline & \multicolumn{2}{c}{ US/Canada based carrier } & \multicolumn{2}{c}{ Non US/Canada based carriers } \\
\cline { 2 - 5 } & Return & t-value & Return & t-value \\
\hline CAR(-5,5) & $-4.55 \%$ & $-3.14 * * *$ & $0.35 \%$ & 0.19 \\
\hline CAR(-1,5) & $-3.46 \%$ & $-2.99 * * *$ & $0.02 \%$ & 0.01 \\
\hline CAR(-1,4) & $-3.53 \%$ & $-3.29 * * *$ & $-0.33 \%$ & -0.17 \\
\hline CAR(-1,3) & $-3.28 \%$ & $-3.35 * * *$ & $1.56 \%$ & 0.82 \\
\hline CAR(-1,2) & $-3.72 \%$ & $-4.25 * * *$ & $1.34 \%$ & 0.71 \\
\hline CAR(-1,1) & $-3.23 \%$ & $-4.25 * * *$ & $0.18 \%$ & 0.10 \\
\hline CAR(-1,0) & $-3.09 \%$ & $-4.99 * * *$ & $0.75 \%$ & 0.40 \\
\hline \#of observation & \multicolumn{7}{c}{} & 13 \\
\hline
\end{tabular}

* t-statistics at the $10 \%$ significance level,**5\% level,***1\% level

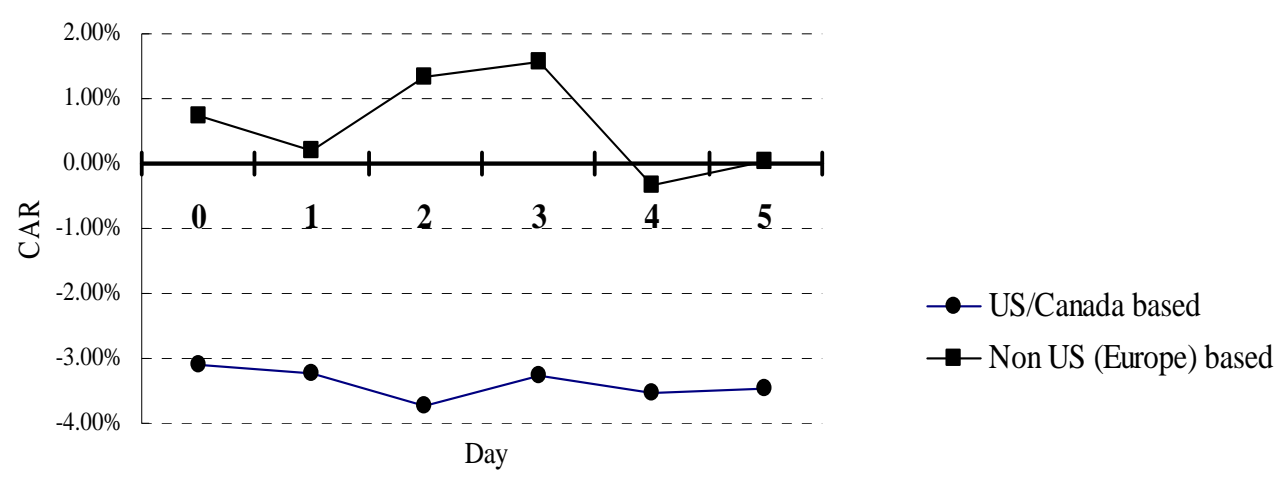

Figure 3 CARs of US/Canada-based and Non-US/Canada carriers

Table 3 and Figure 4 show the CAR values of U.S./Canada-based carriers categorized with the three-dimensional expansion model. There are distinct differences between the three categories in their CAR values; the CAR values for the segment-expansion cases were the most negative and were statistically significant at the $1 \%$ level. The CAR values for the business-diversification cases were also negative, but statistically significant in only some cases. The CAR values were not statistically significant for geographical expansion. 
Table 3 Returns by diversification patterns (US/Canadian carriers)

Geographical Segment expansion Business expansion diversification

\begin{tabular}{|c|c|c|c|c|c|c|}
\hline & Return & t-value & Return & t-value & Return & t-value \\
\hline $\operatorname{CAR}(-5,5)$ & $-0.15 \%$ & -0.06 & $-6.91 \%$ & $-2.70 * * *$ & $-3.78 \%$ & $-1.72 *$ \\
\hline CAR(-1,5) & $-0.30 \%$ & -0.16 & $-7.73 \%$ & $-3.78 * * *$ & $-1.11 \%$ & -0.64 \\
\hline $\operatorname{CAR}(-1,4)$ & $-1.32 \%$ & -0.77 & $-6.89 \%$ & $-3.64 * * *$ & $-1.86 \%$ & -1.15 \\
\hline CAR(-1,3) & $-0.72 \%$ & -0.46 & $-6.36 \%$ & $-3.68 * * *$ & $-1.71 \%$ & -1.16 \\
\hline CAR(-1,2) & $-1.02 \%$ & -0.73 & $-7.30 \%$ & $-4.72 * * *$ & $-1.77 \%$ & -1.34 \\
\hline $\operatorname{CAR}(-1,1)$ & $-1.02 \%$ & -0.85 & $-6.18 \%$ & $-4.62 * * *$ & $-1.79 \%$ & -1.56 \\
\hline $\operatorname{CAR}(-1,0)$ & $-0.63 \%$ & -0.63 & $-5.64 \%$ & $-5.16 * * *$ & $-1.93 \%$ & -2.06 \\
\hline \#of observation & & 7 & & 9 & & 11 \\
\hline
\end{tabular}

$*$ t-statistics at the $10 \%$ significance level, ${ }^{* * 5 \%}$ level, ${ }^{* * *} 1 \%$ level

Table 4 and Figure 5 show the CAR values for non-U.S./Canada-based carriers. The CAR values for geographical expansion and segment expansion were not statistically significant, while the CAR values for business diversification were negative and significant in some cases.

A comparison of Tables 3 and 4 indicates that the market responses to U.S./Canada-based carriers differed from those to non-U.S./Canada-based carriers. Segment expansion by U.S./Canada-based carriers and business diversification by non-U.S./Canada-based carriers were negatively valued by the market.

Table 4 Returns by diversification patterns (Non-US/Canadian carriers)

\begin{tabular}{lcccccc}
\hline & \multicolumn{2}{c}{ Geographical expansion } & \multicolumn{2}{c}{ Segment expansion } & \multicolumn{2}{c}{ Business diversification } \\
\cline { 2 - 7 } & Return & t-value & Return & t-value & Return & t-value \\
\hline CAR(-5,5) & $0.89 \%$ & 0.33 & $0.88 \%$ & 0.20 & $-1.43 \%$ & -1.48 \\
\hline CAR(-1,5) & $1.23 \%$ & 0.56 & $1.24 \%$ & 0.29 & $-4.00 \%$ & $-1.69^{*}$ \\
\hline CAR(-1,4) & $0.64 \%$ & 0.32 & $3.05 \%$ & 0.71 & $-5.16 \%$ & $-2.35^{* *}$ \\
\hline CAR(-1,3) & $1.61 \%$ & 0.87 & $4.61 \%$ & 1.07 & $-0.61 \%$ & -0.31 \\
\hline CAR(-1,2) & $1.42 \%$ & 0.86 & $4.45 \%$ & 1.03 & $-0.93 \%$ & -0.52 \\
\hline CAR(-1,1) & $0.42 \%$ & 0.29 & $2.46 \%$ & 0.57 & $-1.95 \%$ & -1.26 \\
\hline CAR(-1,0) & $1.49 \%$ & 1.28 & $3.10 \%$ & 0.72 & $-2.80 \%$ & $-2.21^{* *}$ \\
\hline \#of observation & \multicolumn{7}{c}{2} & 3 \\
\hline
\end{tabular}

$*$ t-statistics at the $10 \%$ significance level, ${ }^{* * 5 \%}$ level, $* * * 1 \%$ level 


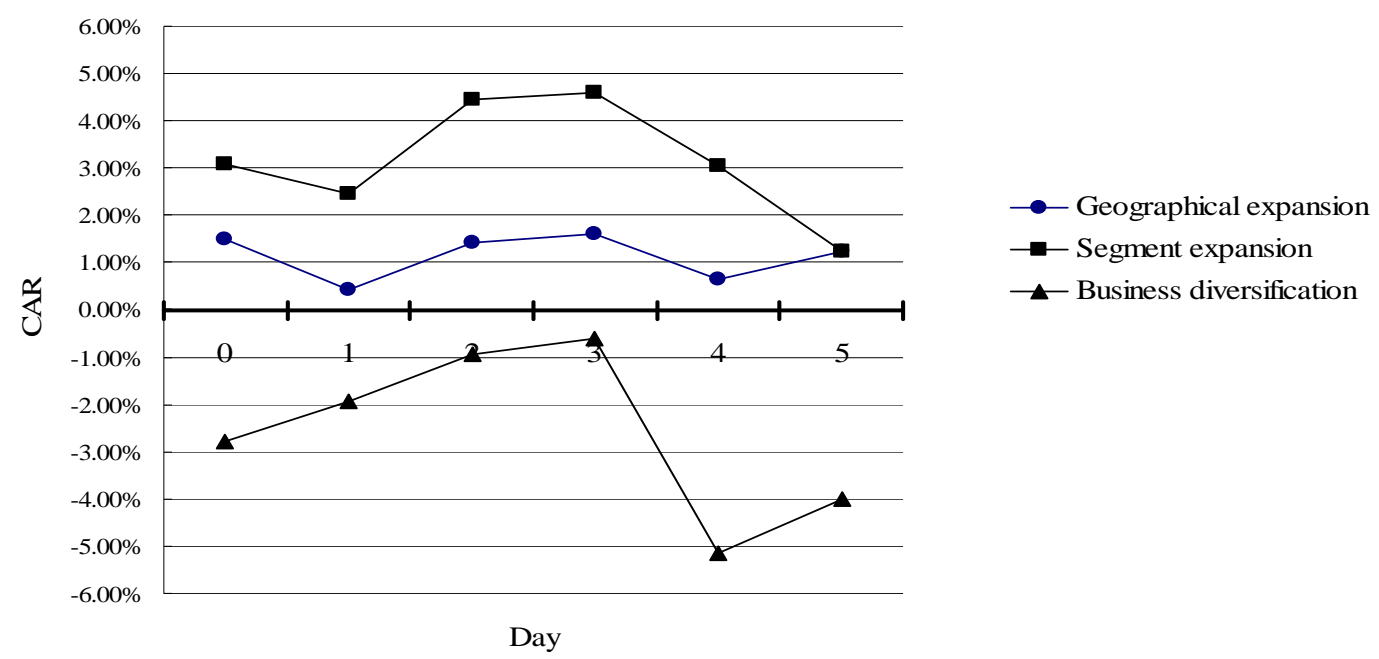

Figure 5 CARs of Non-US/ Carada-based carriers

\section{Evaluation of hypotheses}

The event-study analysis based on daily stock-price data led us to the following findings regarding our three hypotheses.

First, the results in Table 1 and Figure 2 do not support hypothesis H-1. These demonstrate the uniqueness of market responses to inter-firm relationships in the telecommunications industry different to that in other industries such as in financial and banking businesses as previously discussed. The reason for the difference has not yet been identified. However, the results indicate that investors do not necessarily appreciate inter-firm relationships conducted by firms in the telecommunications industry at least from the viewpoints of short-term investment or arbitrage. It can therefore be stated that investors seem to recognize some uniqueness in the characteristics of the telecommunications industry.

At this point, let us focus on the business environment and correlated business processes. Telecommunications carriers employ facilities on a huge scale such as optic-fiber cables, switches, routers, computer systems, buildings and other peripheral amenities and consequently their businesses are composed of larger numbers of operations. As the authors have already discussed, these business processes are not well standardized within the industry in contrast to other industries (Shiraishi and Iijima, 2008b). In such an environment, the numbers of procedures should be 
identified and conducted to accomplish planned inter-firm relationships. These transitions also require much longer periods compared to that in other industries. As the investors and stakeholders of telecommunications carrier firms are aware of these business environments and characteristics, they therefore they do not appreciate announcements of inter-firm relationships in the industry in the short term. We also need to note that middle or long-range responses by the market should help to clarify misunderstanding.

Table 1 and Figure 2 have the results for hypothesis H-2. Although they indicate that geographical expansion seems to be more favorably evaluated than other types of relationships, the differences between the responses for each type are not statistically meaningful, and only responses to business diversification can be identified as meaningfully negative. In addition, we need to note that business diversification is negatively valued and is statistically supported. This does not represent a clear difference in market responses between the three types of relationships, but the results indirectly indicate the possibility of a difference. Table 3 and Figure 4, and Table 4 and Figure 5 show the results for the hypothesis from a different aspect, i.e., analysis separated into U.S./Canada-based and non-U.S./Canada-based carriers. There are distinct differences between the CAR values for U.S./Canada-based carriers and nonU.S./Canada-based carriers. The segment-expansion alliances of U.S./Canada-based carriers are negatively valued, while the business-diversification alliances of nonU.S./Canada-based carriers are negatively valued. Responses to geographical expansion are generally not significant.

These results imply that there may be a possibility of supporting hypothesis $\mathrm{H}-2$, but this is not certain. The authors' understanding is that these results are also correlated to the discussion on $\mathrm{H}-1$ in that short-term market responses are generally not favorable to inter-firm relationships in the industry.

The differences in market responses between U.S./Canada-based and nonU.S./Canada-based firms may reflect differences between their respective market environments. Statistically significant negative responses were obtained regarding inter-firm relationships by U.S./Canada-based firms, which refute hypothesis H-3. This is the opposite to what the authors had expected and they recognize that there is a need for discussion on the relationships between business and regulatory environments, investors' expectations, and the intentions of corporate managers. One the reasons for the results will be discussed in the following subsection. 


\section{Strategies for inter-firm relationships}

Through scrutinizing the results, evaluations, and discussions in the preceding sections, the authors focused on several aspects that are required to establish interfirm-relationship strategies in the telecommunications industry.

The first issue to be identified was the correlation between managers' intentions and expectations by investors or stakeholders in firms. Firms usually enter into interfirm relationships to strengthen their competitiveness and managers involved in the decisions then may expect favorable responses or evaluations based on the decisions by investors or shareholders. As Barney (2002) and Jongmoo, et al. (1999) noted, the stock price or market value of firms reflects investors' expectations about real economic variables in the future. The CAR values may reflect the market view of the future performance of individual firms. The results demonstrated in this research, however, indicate that shareholders' expectations differ at least within short-term windows. Several types of circumstances that create these kinds of results can be suggested-(1) managers misunderstand shareholders' responses, (2) managers enter into these relationships with expectations of such results, and (3) positive shareholder responses can be expected in the middle or long term but not in the short term. There is no clear evidence explaining which of these ((1)-(3)) is correct and analysis and discussion are expected on these issues in further research. However, the fact that shareholders and investors do not necessarily evaluate announcements of inter-firm relationships being formed positively at least in the short term, implies that managers have to develop inter-firm strategies by understanding the stock market environment and their accountability to the market.

The second aspect correlated to the characteristics of the industry has been identified and has already been referred to in the previous section. As was discussed, it may take a long time and require a large number of procedures to accomplish interfirm relationships particularly pursuing M\&A in the telecommunications industry and this circumstance results from its nature and characteristics. In addition, the results of the event study demonstrated that investors may recognize this circumstance and do not expect improvements in the corporate value at least within the short term. Managers then have to understand such behaviors by investors and responses and strategies need to be derived to respond to market behaviors.

The first of these is for managers to respond directly to the stock market. They have to demonstrate that inter-firm relationships are based on long-range strategies and they have to provide explanations of middle- and long-term strategies and transition plans for the purpose of pursuing inter-firm relationships. 
Second, managers who establish strategies for accelerating transition processes required for pursuing inter-firm relationships will be positively evaluated by the stock market. How to harmonize business processes with their counterpart in inter-firm relationships and standardize business processes within the industry are key factors regarding this issue. These are derived from the authors' research (Shiraishi and Iijima, 2008b).

With regard to evaluating hypothesis $\mathrm{H}-3$, a negative valuation of segment expansion by U.S./Canada-based firms suggests that these are not recognized as preferred strategies by shareholders. Most likely, investors have recognized that a firm doing business in one segment will not have any special advantage or capacity for business in a different segment; in other words, firms operating in each of the local, long-distance, and mobile telecommunication markets are assumed to have distinct capabilities by investors in U.S. and Canadian markets. Investors in nonU.S./Canadian markets may believe, in contrast, that segment expansion is more akin to entering a similar business. Although the reason for such differences between the two market areas is unclear, managers should take into account the likely market response when they consider segment expansion in the U.S./Canadian market or business diversification in either the U.S./Canadian markets or markets in other countries.

\section{CONCLUSIONS}

The authors evaluated inter-firm relationships in the telecommunications industry based on a typology of such relationships within it.

This research should be useful in two ways. First, it provides analysis of how stock markets tend to respond to the announcement of inter-firm relationships in the industry, and the results have important implications for managers seeking to develop strategies; our methodology also offers a framework for further research. Second, confirmation of the accepted characteristics of the telecommunications industry, as discussed earlier, demonstrates the usefulness of the framework and a typology that the authors have applied.

The findings from this research enable a better understanding of stock-market responses to inter-firm relationships and strategies. Although a considerable number of alliances and M\&A events have taken place, the empirical results obtained in this research demonstrate that investors have not always responded favorably in the short term to these alliances. In addition, the market reaction has differed depending on the apparent purpose of individual alliances, and depending on whether U.S./Canada- 
based firms or non-U.S./Canada-based firms were involved. Managers in the telecommunications industry should take these findings into consideration when studying strategic alliances or M\&A opportunities. They therefore need to respond to these evaluations by investors.

Several issues still warrant further research.

First, this research has focused on alliances and M\&A events within the telecommunications industry where both or all the partners in the relationships were telecommunications carriers. However, many alliances initiated by telecommunications firms are targeted toward firms in other industries. Even though such relationships have been analyzed (Wilcox et al., 2001, further research focusing on wider aspects of the telecommunications business would be valuable. In addition, the cases and data used in our research were based on a single media source. There is a possibility of bias in the information we used to evaluate the inter-firm relationships. Therefore, this study may be complemented by research based on other data sources.

Second, the methodology for evaluating stock-market responses can be refined. In this study, the authors evaluated short-term responses. The analysis of medium- and long-term responses will provide more complete findings regarding the value of interfirm relationships from both practical and academic perspectives.

Third, this research did not delve into telecommunications firms' reasons for preferring equity-based inter-firm relationships or the regulatory issues related to these preferences. Although research on this topic has been done for other industries, such as that by Carette and Dussauge (1999), the telecommunications industry has not yet been examined in this regard. An examination of these matters with respect to the telecommunications industry, compared with other industries, could lead to important new findings. In addition, we need to discuss which types of regulatory systems would be the most advantageous in the telecommunications industry, and this can be facilitated by comparing its trends with those in other regulated industries from the standpoints of competition and growth.

\section{REFERENCES}

Barney, J. B. (2002). Gaining and sustaining competitive advantage ( $2^{\text {nd }}$ ed.). Upper Saddle River, NJ: Prentice Hall.

Baroncelli, A. (1998). Telecom Italia: Merging five companies into one. Long Range Planning, 31, 377-395. 
Bessler, W., \& Murtagh, J. P. (2002). The stock market reaction to cross-border acquisitions of financial services firms: An analysis of Canadian banks. Journal of International Financial Markets, Institutions, and Money, 12, 419-440.

Brock, G. W. (1998). Telecommunications policy for the information age. Cambridge, MA: Harvard University Press.

Campbell, J. Y., Lo, A. W., \& MacKinlay, C. (1997). The econometrics of financial markets. Princeton, NJ: Princeton University Press.

Carette, B., \& Dussauge, P. (1999). Alliances versus acquisitions: Choosing the right option. European Management Journal, 18, 63-69.

Chan-Olmsted, S., \& Jamison, M. (2001). Rivalry through alliances: Competitive strategy in the global telecommunications market. European Management Journal, 19, 317-331.

Curwen, P. (2001). Rivalry through alliances: A rejoinder to Chan-Olmsted and Jamison. European Management Journal, 19, 678- 681.

Davidson, D. and Worrell, D. (1992). The effect of product recall announcements on shareholder wealth. Strategic Management Journal, 13, 467-473.

Ely, D., \& Song, M. H. (2000). Acquisition activity of large depository institutions in the 1990s: An empirical analysis of motives. The Quarterly Review of Economics and Finance, 40, 467-484.

Faulhaber, G. (2002). Network effects and merger analysis: Instant messaging and the AOL-Time Warner case. Telecommunications Policy, 26, 311-333.

Graack, C. (1996). Telecom operators in the European Union: Internationalization strategies and network alliances. Telecommunications Policy, 20, 341-355.

Hart, J. R., \& Apilado, V. P. (2002). Inexperienced banks and interstate mergers. Journal of Economics and Business, 54, 313-330.

Hill, D. C. (1997). Monitoring performance and ensuring quality in drug discovery alliances. DDT, 2(1), 29-33.

Jamison, M., \& Chan-Olmsted, S. (2002). Rivalry through alliances: Competitive strategy in the global telecoms market. A reply to Curwen. European Management Journal, 20, 95-97.

Jongmoo, J. C., Hauser, S., \& Kopecky, J. K. (1999). Does the stock market predict real activity? Time series evidence from the G-7 countries. Journal of Banking and Finance, 23, 1771-1792.

Joshi, M. P., Kashlak, R. J., \& Sherman, H. D. (1998). How alliances are reshaping telecommunications. Long Range Planning, 21(4), 542-548.

Kahn, A. E. (1997). The economics of regulation. Cambridge, MA: MIT Press. 
Kale, P., Dyer, J. H. Dyer, \& Singh, H. (2002). Alliance capability, stock market response, and long-term alliance success: the role of the alliance function. Strategic Management. Journal, 23, 747-767.

Kelm, K. M., Narayama, V. K., \& Pinches, G. E. (1995). Shareholder value creation during R\&D innovation and commercialization stage. Academy of Management Journal, 38, 770-786.

Koh, J., \& Venkataraman, N. (1991). Joint venture formation and stock market reaction. Academy of Management Journal, 34, 626-657.

Laffont, J. J., \& Tirole, J. (2001). Competition in telecommunications. Cambridge, MA: MIT Press.

MacKinlay, A. C. (1997). Event studies in economics and finance. Journal of Economic Literature, 35, 13-39.

Mitchell, M. L., \& Mulherin, J. H. (1996). The impact of industry shocks on takeover and restructuring activity. Journal of Financial Economics, 41(2), 193-229.

Oh, J. G. (1996). Global strategic alliances in the telecommunications industry. Telecommunications Policy, 20, 713-720.

Porter, M. E. (1985). Competitive advantage. New York: The Free Press.

Rad, A. T., \& Van Beek, L. (1999). Market valuation of European bank mergers. European Management Journal, 17, 532-540.

Shiraishi, N., \& Iijima, J. (2008a). Inter-firm relationships in the telecommunications industry: Characteristics and typology. Proceedings of International Conference on Business and Information 2008, Korea, No. 431.

Shiraishi, N., \& Iijima, J. (2008b). Business process based view of inter-firm relationships. Proceedings of the $12^{\text {th }}$ Pacific Asia Conference of Information Systems, China, 188-197.

Trillas, F. (2002). Mergers, acquisitions, and control of telecommunications firms in Europe. Telecommunications Policy, 26, 269-286.

Vogelsang, I., \& Mitchell, B. M. (1997). Telecommunications competition: The last 10 miles. Washington, DC: The AEI Press.

Wilcox, H. D., Chang, K. C., \& Grover, V. (2001). Valuation of mergers and acquisitions in the telecommunications industry: A study on diversification and firm size. Information and Management, 38, 459-471.

Yoshino, M. Y., \& Rangan, U. S. (1995). Strategic alliances: An entrepreneurial approach to globalization. Boston: Harvard Business School Press. 
